\title{
Diagnostics Features and Results Estimation of Chronic Colostasis Investigation in Children
}

\author{
Akilov Khabibulla', Saidov Farkhod ${ }^{2}$, Khodjimuhamedova Nigora $^{3}$ \\ ${ }^{1}$ Department of Children Surgery, Republican Research Centre of Emergency Medicine, Tashkent, Uzbekistan \\ ${ }^{2}$ Department of Children Surgery, Tashkent Post-Graduate Medical Institute, Tashkent, Uzbekistan \\ ${ }^{3}$ Department of Surgery, Republican Research Centre of Emergency Medicine, Tashkent, Uzbekistan \\ Email: medsaidov@mail.ru
}

Received 15 November 2013; revised 27 December 2013; accepted 16 January 2014

Copyright (C) 2014 by authors and OALib.

This work is licensed under the Creative Commons Attribution International License (CC BY).

http://creativecommons.org/licenses/by/4.0/

c) (i) Open Access

\section{Abstract}

The purpose of the research is the applications of various methods of research and study of their results at chronic colostasis in children. Material and Methods: In the Republican Research Centre of Emergency Medical Care in Tashkent since 2006 till the present time in the branch of children's surgery, 75 children were treated with chronic colostasis at the age of from 3 months till 14 years. With the purpose of the confirmation of the diagnosis, the children were examined according to the standards accepted at the centre: USG, coprological analysis, identification of the intestinal microflora, rectal manual examination, colonofibrocopy, histological investigation of the colon biopsies samples, roentgenocontrast investigation of the colon irrigography, multisliced computed tomography (MSCT) of the colon, definition of anal muscles contractile function. Results and Discussion: In 35 (46.7\%) studied children, there was diagnosed dolichosigma, in $14(18.7 \%)$ -dolichocolon or dolichomegacolon, in 14 (18.7\%)-Hirschsprung's disease, in 1 (1.3\%)-congenital narrowing of the anal channel, in 1 (1.3\%)-Pair's syndrome, in 10 (13.3\%)-functional constipations. Conclusions: Any of known methods at the isolated application does not give absolute reliance of correctness of verification of the diagnosis, especially in heavy cases, at a divergence of clinical findings and data of the patient investigation. Each of methods has the restrictions at application and interpretation of results. The examination of children with chronic constipations should be complex and gradual, and at the subsequent diagnostic stage, the clinician should determine individually in each concrete case.

\section{Keywords}

Chronic Colostasis; Diagnostics; Children 


\section{Background}

Disorder of the regular intestine emptying, that is, chronic constipation or chronic colostasis, is one of the symptoms most frequently occurring in the gastroduodenal practice. The incidence of the constipation among the children's population was found in 5\% - 10\% [1]-[4]. It is known that chronic constipations at their long development and absence of adequate therapy result in such complications, as secondary encopresis, diseases of genitourinary system and others [5]-[8]. Children suffering from chronic constipations, as a rule, were included into the group of children frequently ill, and they complain to fast fatigue, poor progress in education that is the sign of the general body intoxication [9]-[11]. The majority of such patients have disturbances of functions of the other parts of the gastrointestinal tract: dyskinesia of the biliary ways, reactive pancreatitis, and chronic gastroduodenitis etc. At the late referring and long development of disease, the exhaustion of body reserve forces and formation of irreversible changes in the colon may be observed on a background of motor functional disorders [12]-[15].

Diagnostics, first of all, is directed to exception of organic and extraintestinal diseases. However, the majority of researchers believed that in 95\% of cases, the etiological factor cannot be identified at examination [16]-[19]. Such types of chronic constipations are named functional, idiopathic. Some authors describe them by roentgenological anatomy of the colon-dolichocolon, dolichosigma, idiopathic megacolon, megarectum etc., which quite often results in mess and complicates a choice of tactics of examination, treatment and comparative analysis of the long-term results of treatment [20] [21]. Often it is difficult to solve the problem about duration of conservative therapy, especially at the patients without expressed positive dynamics. In a number of cases, there is a necessity for surgical intervention [22] [23]. Development of the precise indications to operative intervention therefore is required depending on a degree of affected colon. With this regards, the large attention is given to exact diagnosis of colostasis.

\section{The Purpose of Research}

Applications of various methods of research and study of their results at chronic colostasis in children.

\section{Material and Methods}

In the Republican Research Centre of Emergency Medical Care in Tashkent since 2006 till the present time in the branch of children's surgery 75 children were treated with chronic colostasis at the age of from 3 months till 14 years, of them $45(60 \%)$ boys and $30(40 \%)$ girls. All patients were admitted with symptoms of acute abdomen: acute appendicitis, acute intestinal obstruction, volvulus of the colon, perforation of the colon, intestinal colic. The large cohort of the patients was at the age of from 3 till 14 years-54 (72\%).

During dynamic supervision in 40 (53.3\%) children admitted to the surgical hospital with the provisional diagnosis of acute appendicitis, in 31 (41.3\%) -with clinical pictures of partial intestinal obstruction, in 1 (1.3\%) - with intestinal bleeding of unknown etiology, in 3 (4\%) - with pain abdominal syndrome the urgent surgical pathology was excluded. With the purpose of the confirmation of the diagnosis the children were examined according to the standards accepted at the centre:

1) Anamnesis (complaints, history of disease, the primary signs of illness, their dynamics, treatment performed).

2) Clinical, laboratory, instrumental investigations (examination, general blood and urine analysis, biochemical blood examination, roentgenoscopy of the chest, ECG, USG, coprological analysis, identification of the intestinal microflora).

3) Special and additional methods of investigation (rectal manual examination, colonofibrocopy, histological investigation of the colon biopsies samples, roentgenocontrast investigation of the colon irrigography, barium passage in the gastrointestinal tract, multisliced computed tomography (MSCT) of the colon, definition of anal muscles contractile function).

\section{Results and Discussion}

In 35 (46.7\%) studied children there was diagnosed dolichosigma, in 14 (18.7\%)—dolichocolon or dolichomegacolon, in 14 (18.7\%)—Hirschsprung's disease, in 1 (1.3\%)—congenital narrowing of the anal channel, in 1 
(1.3\%)—Pair's syndrome, in 10 (13.3\%)—functional constipations.

\subsection{Results of Roentgenological Investigation of the Colon}

All the children underwent the roentgenological investigation of the colon on the device Philips duo diagnost with the purpose to study its anatomic-physiological state and to reveal organic changes.

The study of passage of the contrast mass allows revealing change of the colon sizes, estimation of its evacuator function, finding out signs of organic diseases.

The received roentgenograms were estimated with taking into account anamnesis and clinical characteristics (Table 1). The main roentgenological findings in children suffering from chronic constipations were irregular filing of the colon—in 47 (63\%), incomplete evacuation of the colon—in 40 (53.3\%). The long delay of contrast substance in the colon was noted in $57(76 \%)$ studied patients. The specified symptoms were not isolated in many cases.

The individual analysis of roentgenograms showed the specific combinations of the roentgenological findings allowing making diagnosis:

- functional disorders of the large intestine motility looking-like spastic colitis (delayed barium passage, intermitting narrowing of the colonlumen, increase of tonus and increase of haustration) and atonic colitis (slowing barium passage, intermitting dilatations of the colon lumen, decrease in tonus and smoothing haustration);

- dolichosigma—lengthening of the sigmoid intestine, additional loops (Figure 1);

Table 1. Roentgenological findings revealed in children with chronic constipations.

\begin{tabular}{cc}
\hline Roentgenological findings & Frequency of changes, abs. (\%) \\
\hline Irregular filling of the large intestine & $47(63)$ \\
Incomplete evacuation of the large intestine & $40(53)$ \\
Additional loops & $12(16)$ \\
Dilatation of the large intestine & $30(40)$ \\
Smoothing down of haustra & $19(25)$ \\
Spastic syndrome & $17(23)$ \\
Prolonged (>48 hours) retention of contrast agent & $57(76)$ \\
Insufficiency of the sphincter apparatus & $16(21)$ \\
Insufficiency of the ileocecal valve & $8(11)$ \\
Reflux (ileocecal) & $7(9)$ \\
\hline
\end{tabular}

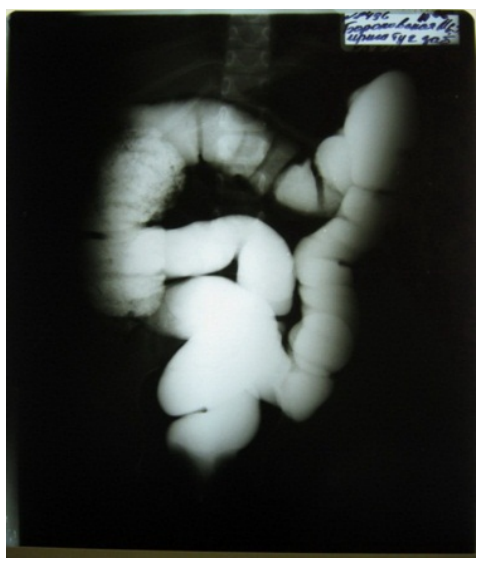

Figure 1. Irrigography. Dolichosigmaas "three-barrel". 
- dolichomegacolon—stable lengthening and dilation of the colon (Figure 2);

- megarectum—stable increase in the sizes of the rectum;

- Hirschsprung's disease-sharp narrowing of distal parts of the large intestine and sharp dilation of the colon above the narrowing (Figure 3);

- megacolon-stable dilation of the colon (Figure 4).

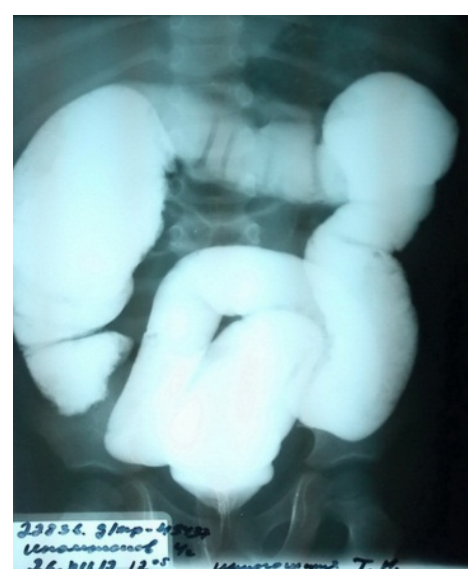

Figure 2. Irrigography Dolichomegacolon.

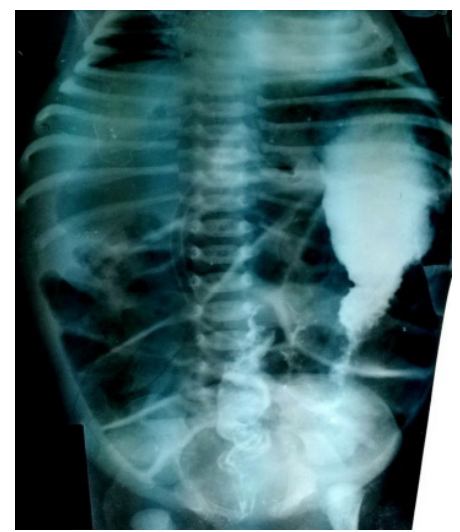

Figure 3. Irrigography. Hirschsprung's disease.

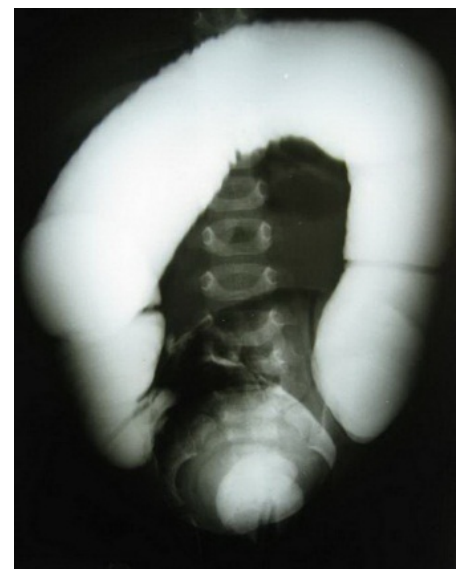

Figure 4. Irrigography. Megacolon. 
Irrigography can be used for children of any age, but it is necessary to take into account the volume of radial loading. With the help of this method it is possible to receive the information about anatomic-physiological state of the large intestine, to reveal organic lesions, to determine the sizes of a body and its evacuating function. However, to estimate a state of the mucosa and to find out complications probably is not possible always. The study appeared to be highly informative in the whole group of children with chronic constipations: the diagnosis confirmed by other methods was established in 70 (93.3\%) studied children. With the help of irrigography the diagnosis was not verified in $5(6.7 \%)$ patients. However if to study separately a group of children with organic diseases of the large intestine, which included 65 (86.7\%) patients, the diagnosis was established and confirmed by the other methods in 62 (95.4\%) patients, and in 3 (4.6\%) the false negative results were received.

\subsection{Results of the Functional Methods of Investigation of the Large Intestine (Sphincterometry)}

With the purpose of study on nervous-reflectory activity of the obturative apparatus of the rectum 31 (41.3\%) children underwent sphincterometry on electrosphincterometer developed by the researchers of the Scientific Research Institute of Proctology of the Ministry of Health of the Russian Federation, thus the contractile force of internal and external sphincter was measured at spontaneous and reflex contractions. In 10 (13.3\%) patients, having Hischsprung's disease by the data of irrigography, the diagnosis was confirmed by sphincterometry (absence or reduction of the anorectal reflex, sphincter hypotony, reduction of the intestine ability to filling).

Of 18 (24\%) patients with dolichosigma by the data of irrigography in 13 (17.3\%) children the anorectal reflex was preserved at sphincterometry and in $5(6.7 \%)$ it was reduced.

In $3(4 \%)$ patients the anorectal reflex was absent, though by the data of irrigography the suspicion of an organic lesion of the intestine in them did not arise.

The comparison of the results of sphincterometry with the clinical evidences showed that external and internal sphincters were at the state of tonic contraction at not complicated constipation, as well as in healthy children, but in the patients with persistent constipation the tonus of anal sphincter was increased. It is considered, that such increase is compensatory, and at the expense of the external sphincter at the uncomplicated constipation hermetic closing occurred, that is, spontaneous stool was not formed. At presence of encopresis, on the contrary, the tension of and external and internal sphincters at a rest state and under internal contraction reduced and fecal spots appeared.

The more prolonged disease induced the more significant changes of manometry.

Thus, the decrease in such manometry parameters as electrosphincterometry indicated about secondary changes of activity of the closing apparatus of the rectum in children with chronic constipation.

The results of sphincterometry we took into account further at choice of physiotherapy.

Thus, after examination with use of roentgenological, endoscopic and functional methods at 11 (14.7\%) patients there was observed a divergence in the results of examination and clinical symptoms, that did not allow formulating precisely the diagnosis:

The prescription of the functional methods has the marked restrictions with regards to age, and the information received was often inconsistent, particularly if children received repeatedly treatment with use of physiotherapy. Nevertheless, the functional methods of examination play the significant role, allowing, on the one hand, to differentiate cologenous type of constipation from the proctogenous and to choose the further tactics of treatment, and, on the other hand, to suspect organic diseases of the large intestine on the basis of absent anorectal reflux that was observed in 3 (4\%) studied children.

\subsection{Results of Endoscopic Examination of the Large Intestine}

As it is known, the phenomena of coprostasis can arise on a background of the changed mucous layer of the large intestine. On the other hand, these changes are induced by the more or less long coprostasis. Therefore in order to verify changes of a mucous layer of the large intestinein 15 (20\%) patients, which were admitted to the clinic repeatedly, after more than once examinations and ineffective treatment at a residence, and by the data of irrigography had the signs of colitis, we performed colonofibroscopy with apparatus Olympus PCF 20 with the further microscopic study of the biopsy samples obtained. This group included also patients whose diagnosis failed to be established atroentgenological examination.

The various mucosa changes of the large intestine were found in the majority of children with constipation. 
So in all 15 (100\%) studied patients there were observed inflammatory changes-colitis (Figures 5(a) and (b)), of them in 5 (33.3\%) children there was revealed irritable colon syndrome. In 8 (53.3\%) patients there was found dolichosigma, which was characterized by lengthening of the sigma and increase of the intestinal lumen, increased tonus of the sphincter apparatus. Two (13.3\%) children had anal fissureson a background of inflammatory changed mucosa of the large intestine (Table 2).

\subsection{Results of Histological Investigation of the Large Intestine}

All children, who underwent colonoscopy in order to confirm the clinical diagnosis, to evaluate the state of nervous-muscular apparatus, vascular bed and for exclusion of disease the histological investigation of the biopsy samples of the mucosa of the large intestine. We used histological criteria of a chronic inflammation of the large intestine, marking out superficial and diffusive colitis associated with partial or expressed atrophy.

In 11 (73.3\%) from 15 (20\%) children the revealed inflammation had superficial character, in $1(6.7 \%)$ there was diffusive inflammation, in 1 (6.7\%)—subatrophic inflammation, in 2 (13.3\%) children there were found erosions of a mucous layer of the large intestine.

At the superficial inflammation there was noted impression of the cylindrical epithelium, increase in number of goblet cells. The cellular infiltration was presented by lymphocytes, plasmocytes, eosinophils. At presence of atrophy the cellular infiltration was poor, there was noted total impression of epithelium, the marked sclerosis, sharp decrease in quantity of the goblet cells, their absence in the crypts, minimalmyotic activity (Figures 6 and 7).

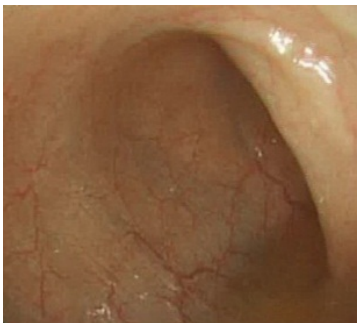

(a)

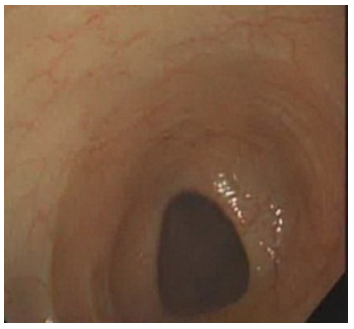

(b)

Figure 5. (a), (b) Colonoscopy. Signs of colitis at dolichosigma.

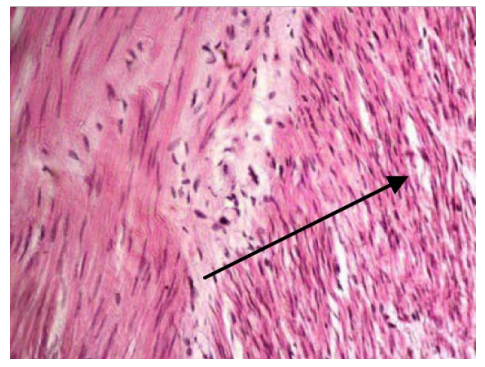

Figure 6. Dysplasia of the nervous ganglion of the large intestine. Gematoksilin and eosin, lens $10 \mathrm{x}$ ocular 10.

Table 2. Endoscopic picture of the mucosa changes of the large intestine in patients with chronic constipation.

\begin{tabular}{ccc}
\hline Type of changes & Number of patients, abs. (\%) \\
\hline Inflammatory process (colitis) & 15 & 100 \\
Signs of irritable colon syndrome & 5 & 33.3 \\
Dolichosigma & 8 & 53.3 \\
Anal fissures & 2 & 13.3 \\
\hline
\end{tabular}


Histological investigation in 1 (20\%) of 5 (33.3\%) children with the preliminary diagnosis of irritable colon syndrome showed subatrophic changes and superficial inflammation of mucosa of the large intestine in 4 (80\%) children.

Of 8 (53.3\%) children with endoscopically revealed dolichosigma histological investigation showed superficial inflammation in 5 (62.5\%), erosion of the mucosa of large intestine in 2 (25\%) and diffusive inflammation in one (12.5\%). In two (13.3\%) children with fissures there was noted superficial inflammation of the mucosa of the large intestine (Table 3).

Thus, the results of histological investigation did not always coincide with endoscopic findings. Histological investigations revealed clear changes in mucous and submucous layers in the intestinal wall.

Endoscopic methods (rectomanoscopy, colonoscopy), particularly in a combination with morphological studies of the biopsy samples allow obtaining of the detailed and reliable information about the state of a mucous layer of the large intestine. The negative feature is the necessity to perform these examinations under anesthesia. This study is insufficiently informative in relation to the organic nature of chronic constipations, becausefails to estimate a condition of the muscular layer of the large intestine, and the results of histochemical investigations of the biopsy samples appeared to be doubtful in 4 (26.7\%) cases.

\subsection{Results of MSCT of the Large Intestine}

The multisliced computed tomography was performed on 40-sliced computed tomography Brilliance of firm Philips with the following parameters: $50-140 \mathrm{mAs}, 80 \mathrm{\kappa B}$, slice thickness $1.5 \mathrm{~mm}$. MSCT investigation was performed with use of water-soluble contrast $76 \%$ trasograph $20 \mathrm{ml}$. diluted with $1.5 \mathrm{l}$ of water at the contrast colonography, or with a forcing air into a lumen of the large intestine at virtual colonoscopy. For the estimation of the state of large intestine there was used 3D reconstruction, 2D multicavitary reconstruction. The form of intestine, its location, contours, haustruation, lumen width along the whole length, presence of deformations of a contour, stenosis, lengthened departments or additional loops of the large intestine were determined. Three-dimensional copy of a lumen of the large intestine allowed revealing cecoileal reflux, malformations of development (dolichosigma, dolichocolon, megacolon, Hirschsprung's disease). The thick of the wall of intestine was measured and evaluated on the axial slices and multiplane reformations.

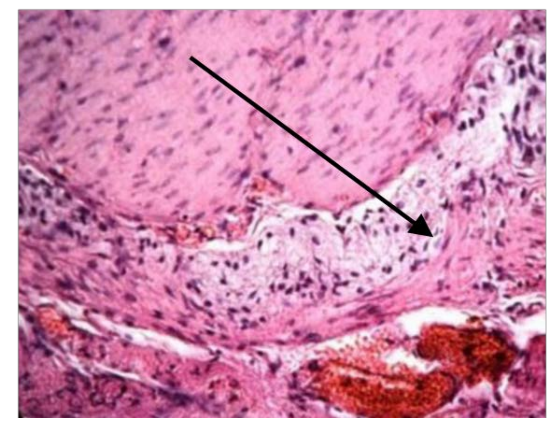

Figure 7. Dystrophic changes of the ganglionic cells of the large intestine. Gematoksilin and eosin. Lens $10 \times$ ocular 10 .

Table 3. Results of histological investigation of the mucous layer of the large intestine in children with chronic constipation and their comparison with the findings of endoscopy, abs. (\%).

\begin{tabular}{|c|c|c|c|c|c|}
\hline \multirow{2}{*}{ Endoscopic findings } & \multicolumn{5}{|c|}{ Histological investigations } \\
\hline & Superficial inflammation & Diffusive inflammation & Subatrophic changes & Erosion & Totally \\
\hline Signs of irritable colon syndrome & $4(26.7)$ & & $1(6.7)$ & & $5(33.3)$ \\
\hline Dolichosigma & $5(33.3)$ & $1(6.7)$ & & $2(13.3)$ & $8(53.3)$ \\
\hline Anal fissure & $2(13.3)$ & & & & $2(13.3)$ \\
\hline Inflammatory process (colitis) & $11(73.3)$ & $1(6.7)$ & $1(6.7)$ & $2(13.3)$ & $15(100)$ \\
\hline
\end{tabular}


On the basis of the results of MSCT dolichosigma was diagnosed in 12 (44.5\%) studied patients, Hischsprung's disease-in 3 (11.1\%), dolichocolon or dolichomegacolon-in 6 (22.2\%), cecoileal reflux-in 3 (11.1\%), malrotation syndrome-in 3 (11.1\%).

The criteria for diagnosis of dolichosigma by data of MSCT were lengthening of the sigmoid intestine with formation of two loops (Figure 8) and more, location of the lengthened loops of the sigmoid intestine in the right departments of the abdominal cavity. Dolichomegacolon was diagnosed on the basis of lengthening and dilatation of the large intestine along its length (Figures 9(a) and (b)). The diagnosis of cecoileal reflux was established on the basis of filling of the small intestine with contrast substance as result of its entering from the large intestine.

\subsection{Results of Ultrasonic Investigation of the Large Intestine and Organs of the abdominal Cavity}

Ultrasound investigation on the apparatus "Hitachi-EUB 500" was used for examination of the pancreatic gland, liver, gallbladder, kidneys, large and straight intestine.

Transabdominal ultrasound investigation of the large intestine with filling of its lumen with $0.9 \%$ solution of the sodium chloride without use of spasmolitic agents allowed revealing anatomic-topographic location of the large intestine in the abdominal cavity, structural changes of the colon wall, its tonus and character of peristalsis.

In forty five (60\%) children there were observed characteristic echographic signs of degenerative disorders: irregular thickening of the intestinal wall, loss of its stratified structure with change of echostructure and echogenecity, irregular haustration, haustra bottom flattening. There were found inflammatory changes in the large intestine, more than $5 \mathrm{~mm}$ flattening of its wall, uneven of internal and external contours, dilatation of the large intestine lumen, peristalsis decrease (Figures 10(a) and (b)).

Polyorgan pathology was diagnosed in 35 (46.7\%) patients with use of ultrasound method: change of the form, density of a wall of the gallbladder with signs of chronic cholecystitis in 9 (12\%), increase in liver sizes from 1.0 up to $3.5 \mathrm{~cm}$ from the edges of the costal arch, condensation of the liver parenchyme-in 28 (37.3\%), increase in echogenecity of the pancreatic gland-in 17 (22.7\%), various changes of form, diameter, compression of a straight intestine-in 15 (20\%). In five (6.7\%) patients there were noted inflammatory changes of kidneys, signs of hydronephrosis.

The ultrasonic study of the large intestine and organs of the abdominal wall allows in time to diagnose an initial stage of colostasis and polyorgan pathology in children with chronic constipations.

\subsection{Results of Study of the Intestinal Biocenosis and Coprology}

Coprological examination was performed in 34 (45.3\%) patients. The microscopic investigation of the feces showed that in $26(76.5 \%)$ children prior to the beginning of treatment there was increased quantity of extracellar and in 8 (23.5\%) children of intracellular starch (creatorrhea of I and II types), in 7 (20.6\%) children there

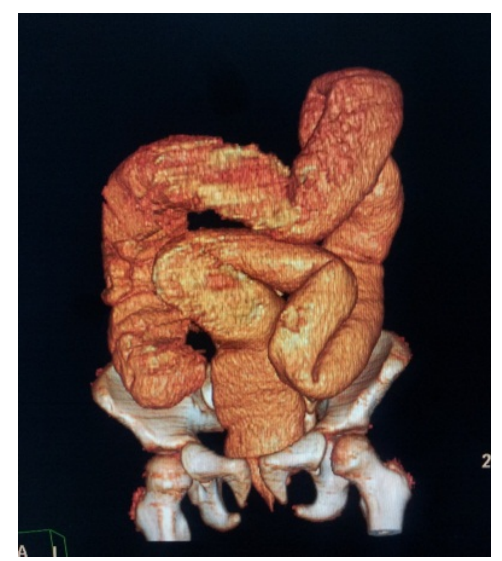

Figure 8. MSCT contrast colonography. Dolichosigma looking-like "double-barrel”, 3D reconstruction. 


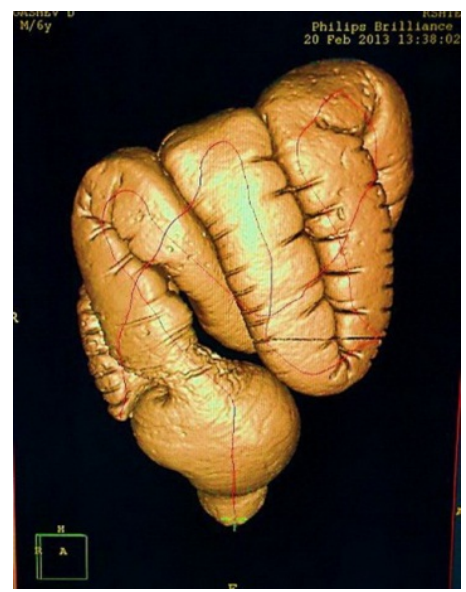

(a)

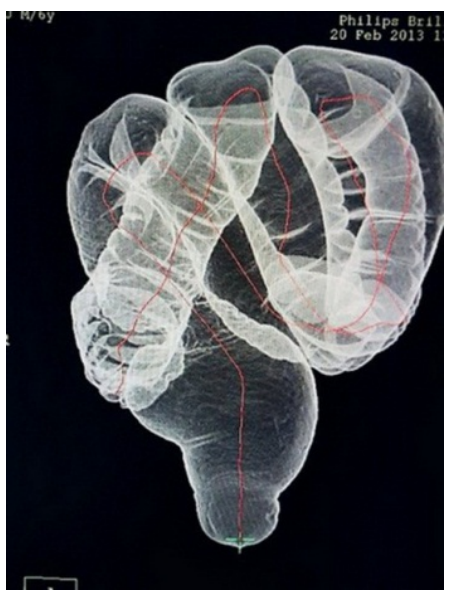

(b)

Figure 9. (a), (b) MSCT virtual colonoscopy. Signs of dolichomegagolon, 3D reconstruction.

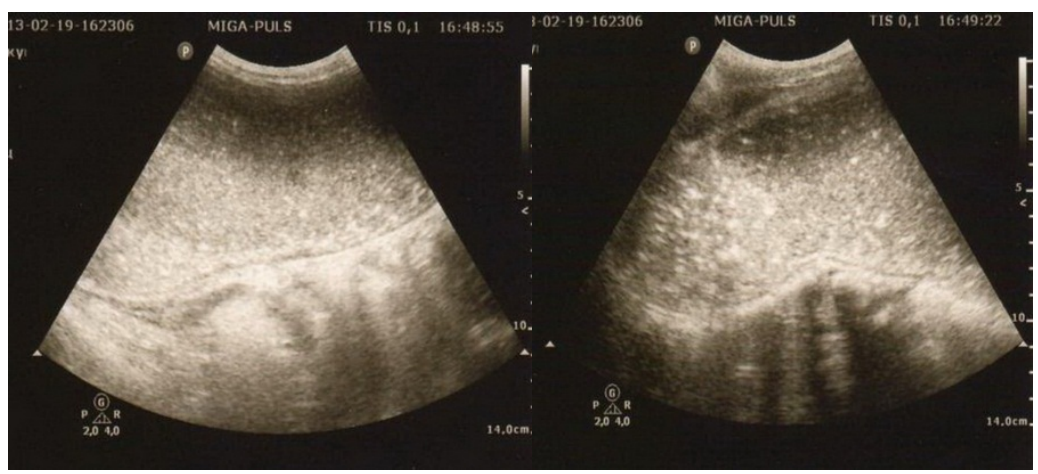

(a)

(b)

Figure 10. (a), (b) Ultrasound investigation of the large intestine. Dilatation of the lumen of the large intestine, smoothness of the haustras.

was revealed amylorea (increase of quantity of neutral fat, soaps fat acids). The all children with chronic constipation underwent the bacteriological examination of feces before and after treatment. The data of the condition of intestinal biocenosis in children with chronic constipations are presented in Table 4.

The qualitative changes of microflora in children with chronic constipations also included appearance of opportunistic microflora (Staphylococcosisaureus and hemolyzing, fungi of sort Candida, proteus), that indicated about defensive abilities of endogenous anaerobic microflora.

Thus, the revealed changes of intestinal biocenosis, which have not so much quantitative how much qualitative character, seem to be confirmation of presence significant disbiotic shifts in the patients with chronic constipations. The quantitative changes consist in insignificant reduction of quantity of endogenous microflora, qualitative-in decrease of its protective properties, growth of colon bacilli with the changed properties and opportunistic microflora. The data obtained gives the basis to believe, that disbiotic disorders are one of mechanisms of formation of chronic constipation in children, which, certainly, requires the appropriate correction.

Features of the various methods are listed in Table 5.

Sensitivity of each method was calculated using the proportion of correct positive test results of all patients, which was determined by the formula of Fletcher. P $(\mathrm{Se}=\mathrm{TP} / \mathrm{D}+* 100 \%)$ where: Se-sensitivity, TP-true positive cases, $\mathrm{D}+$-number of patients with colostasis (Table 6).

\section{Conclusions}

1) Any of known methods at the isolated application does not give absolute reliance of correctness of verifica- 
Table 4. Character of changes of intestinal microflora in children with chronic constipations.

\begin{tabular}{cc}
\hline Qualitative changes & Number of patients in \% \\
\hline Pathogenic microbes of the enterobacteria kind & - \\
Reduction of total number of colon bacilli $<10^{7}$ & 20 \\
Increase in number of lactosa-negative colon bacilli $>10^{5}$ & 22 \\
Hemolytic colon bacilli & - \\
Other opportunistic enterobacteria & 18 \\
Increase in number of non-fermentating bacteria $>10^{4}$ & - \\
Staphylococci (saprophytus, epidermal) & 10 \\
Staphylococcus aureus & 67 \\
Decrease in number of enterococci $<10^{5}$ & 84 \\
Decrease in number of lactobacilli $<10^{7}$ & 93 \\
Decrease in number of bifidobacteria $<10^{9}$ & 12 \\
Increase in number of fungi of sortCandida $>10^{4}$ & \\
\hline
\end{tabular}

Table 5. The advantage and disadvantages of different methods in diagnosis chronic colostasis in children.

\begin{tabular}{|c|c|c|c|c|c|c|c|}
\hline Tasks & Ultrasound & Colonofibrocopy & Irrigography & MSCT & Sphincterometry & $\begin{array}{c}\text { Histological } \\
\text { studies }\end{array}$ & $\begin{array}{l}\text { Microflora of } \\
\text { large intestine }\end{array}$ \\
\hline Comfort & Comfortable & Unpleasant & Comfortable & Comfortable & Unpleasant & Comfortable & Comfortable \\
\hline Radiation exposure & Harmless & Harmless & Radiation exposure & Radiation exposure & Harmless & Harmless & Harmless \\
\hline $\begin{array}{l}\text { Study of the } \\
\text { function }\end{array}$ & Learning & Not learning & Not learning & Not learning & Learning & Not learning & Not learning \\
\hline $\begin{array}{l}\text { Study of the total } \\
\text { thickness of the } \\
\text { intestinal wall, } \\
\text { the deep layers }\end{array}$ & Learning & Not learning & Not learning & Learning & Not learning & Learning & Not learning \\
\hline $\begin{array}{l}\text { Identification of } \\
\text { other pathologies } \\
\text { (oncology, } \\
\text { diverticulum) }\end{array}$ & Learning & Learning & Learning & Learning good & Not learning & Learning & Not learning \\
\hline $\begin{array}{l}\text { Identification of } \\
\text { inflammatory changes }\end{array}$ & Reveals & $\begin{array}{l}\text { Reveals very } \\
\text { good }\end{array}$ & Reveals & Reveals good & Not learning & $\begin{array}{l}\text { Reveals } \\
\text { good }\end{array}$ & Not learning \\
\hline $\begin{array}{c}\text { Evaluation of } \\
\text { anatomy and } \\
\text { topography }\end{array}$ & Not learning & Not learning & Learning & Learning good & Not learning & Not learning & Not learning \\
\hline Possibility Biopsy & No & Yes & No & No & No & No & No \\
\hline Study of microflora & Not learning & Not learning & Not learning & Not learning & Not learning & Not learning & Learning \\
\hline
\end{tabular}

Table 6. Comparative characteristics of methods of investigation of the colon.

\begin{tabular}{|c|c|c|c|c|}
\hline The method of investigation & $\mathbf{N}$ & TP & FN & Se $\%$ \\
\hline Irrigography & 75 & 70 & 5 & 93.3 \\
\hline Ultrasound & 45 & 14 & 31 & 31.1 \\
\hline Colonofibrocopy & 15 & 12 & 3 & 80 \\
\hline Histological studies & 15 & 11 & 4 & 73.3 \\
\hline Sphincterometry & 31 & 20 & 11 & 64.5 \\
\hline MSCT & 27 & 27 & 0 & 100 \\
\hline Microflora of large intestine & 34 & 31 & 3 & 91.2 \\
\hline
\end{tabular}

Note: $\mathrm{N}$-total number of patients; TP—true positive cases; FN—false negative cases; Se—sensitivity Percentage. 
tion of the diagnosis, especially in heavy cases, at a divergence of clinical findings and data of the patient investigation. Each of methods has the restrictions at application and interpretation of results.

2) In the difficult cases, when diagnostics is complicated, and other methods are informative insufficiently, the MSCT allows the most precisely diagnosing pathology of the large intestine. With the help of 3D reconstruction, the colon may be visible in three different planes, and it is possible to obtain slices from the various sites and to evaluate the state of intestine and to choose the technique of surgical treatment.

3) The examination of children with chronic constipations should be complex and gradual, and at the subsequent diagnostic stage, the clinician should determine individually in each concrete case.

\section{References}

[1] Atias, O., Finaly, R., et al. (1991) Erytrocyteacety Lcolinesterase Activity in Hirschprung's Disease in Israel. Journal of Pediatric Surgery, 26, 190-191.

[2] De Vries, P.A. and Cox, K.L. (1985) Surgery of Anorectal Anomalies. Sung. The Clinics of North America, 65, 11391169.

[3] Meier-Ruge, W., et al. (1972) Acetylcholinesterase Activity in Section Biopsys of the Rectum in the Diagnosis of Hirschprungs Disease. Journal of Pediatric Surgery, 7, 11-17.

[4] Si, J.M., Yu, Y.C., Fan, V.J. and Chen, S.J. (2004) Intestinal Microecology and Quality of Life in Irritable Bowel Syndrome Patients. World Journal of Gastroenterology, 10, 1802-1805.

[5] Grigoriev, P.Ya. and Yakovenko, E.P. (1997) Diagnosis and Treatment of the Diseases of the Digestive Organs. 516.

[6] Isakov, Yu.F., Stepanov, E.M. and Mostovaya, S.S. (1985) Diseases of the Large Intestine. Manual on Clinical Endoscopy. In: Savelieva, V.S., Ed., Medicine, 5, 59-63.

[7] McClung, H.J., Boyne, L. and Heitlinger, L. (1995) Constipation and Dietary Fiber Intake in Children. Pediatrics, 96, 999-1000.

[8] Ott, S.J., Vusfeld, M., Wenderoth, D.F., et al. (2004) Reduction in Diversity of the Colonic Mucosa Associated Bacterial Microflora in Patients with Active Inflammatory Bowel Disease. Gut, 53, 685-693.

[9] Koloski, N.A., Talley, N.J. and Boyce, P.M. (2002) Chronic Constipation: Health Care Use and Cost Chronic Constipation. Health Care Use Cost. American Journal of Gastroenterology, 97, 2290-2299.

[10] Lenushkin, A.I. (2004) Children’s Coloproctology. Medicine, 2004, 57-66.

[11] Loening-Bauske, V. (1993) Chronic constipation in children. Castroenterogy, 105, 1557-1564.

[12] Ardatskaya, M.D., Minushkin, O.N. and Ikonnikov, N.S. (2004) Disbacteriosis of the Intestine: Concept, Diagnostic Approaches and Ways of Correction. Opportunities and Advantages of Biochemical Analysis of Feces: The Manual for the Doctors.

[13] Baranova, A.A., Klimanskiy, E.V. and Rimarchuk, G.V. (2002) Children’s Gastroenterology. The Elected Chapters. 499-530.

[14] Dukro, F. (2002) The Constipation: Diagnostics and Tactics of the Management of. Klin. Perspective Gastroenterology, 1, 35-37.

[15] Zaprudnov, A.M. (1991) Problems and Prospects of Children’s Gastroenterology. Pediatria, 9, 4-11.

[16] Klimanskaya, E.V. and Scherbakov, P.L. (2002) Endoscopy in the Gastroenterology. Children's Gastroenterology.

[17] Kopanev, Yu.A. and Sokolov, A.L. (2002) Disbacteriosis of the Intestine: Microbiological, Immunological and Clinical Aspects of Microbiological Disorders in Children.

[18] Minushkin, O.N., Ardatskaya, M.D., Babin, V.N., et al. (1999) Disbacteriosis of the Intestine. Russian Medical Journal, 3, 40-44.

[19] Shenderov, B.A. (1998) Normal Microflora and Its Role in the Supporting of the Human Health. Russian Journal of Gastroenterology, Hepatology, Coloproctology, 1, 61-66.

[20] Flock, M.H. and Wald, A. (1994) Clinical Evaluation and Treatment of Constipation. Castroenterology, 2, 50-60.

[21] Osipenko, M.F. (2005) Mega- and Dolichocolon; Clinical Signs, Risk Factors, Pathogenesis, Diagnostics. Russian Journal of Gastroenterology, Hepatology, Coloproctology, 4, 74-81.

[22] Grigovich, I.N., Shorokhova, N.E. and Iudin, A.A. (1990) Criteria of the Concept "Chronic Constipation” and Their Importance in Children's Surgery and Pediatrics. Pediatria, 10, 62-68.

[23] Mikhailov, A.N. (1994) Radiological Diagnostics in Gastroenterology. Minsk, 647. 